\title{
Effect of Some Physical-Chemical Variables in The Synthesis of Hydroxyapatite by the Precipitation Route
}

\author{
C. García ${ }^{1, a}$, C. Paucar ${ }^{1, b}$, J. Gaviria ${ }^{1, c}$, A. Durán ${ }^{2, d}$ \\ ${ }^{1}$ Universidad Nacional de Colombia Sede Medellín Facultad de Ciencias, Escuelas de Física \\ y Química, A.A. 3840 Medellín, Colombia \\ ${ }^{2}$ Inst. Cerámica y Vidrio (CSIC) Campus de Cantoblanco, 28049 Madrid, Spain \\ a cpgarcia@unalmed.edu.co, bcgpaucar@unalmed.edu.co, cjgarango@unalmed.edu.co, \\ aduran@icv.csic.es
}

Key Words: Hydroxyapatite, Biomedical Applications, Precipitation route, Chemical Properties, Synthesis.

\begin{abstract}
The synthetic hydroxyapatite is a very useful material for numerous applications in medicine as a biomaterial. One of the most economic manufacturing process is the precipitation route. In the present work, synthetic hydroxyapatite was prepared using the precipitation route, starting with aqueous solutions of calcium nitrate $\left(\mathrm{Ca}\left(\mathrm{NO}_{3}\right) \cdot 4 \mathrm{H}_{2} \mathrm{O}\right)$ and ammonium phosphate $\left(\mathrm{H}_{2}\left(\mathrm{PO}_{4}\right) \mathrm{NH}_{4}\right)$. The effects of physical-chemical variables such as $\mathrm{pH}$, temperature, time of agitation, ageing time and heat treatment of the mixture were evaluated. The characterization of the samples obtained in different conditions made possible to conclude about the optimal values of the studied variables for the synthesis of this material in laboratory conditions.
\end{abstract}

\section{Introduction}

The repair of defects in hard tissues is a permanent challenge in orthopaedic and dental applications ${ }^{[1]}$. The hydroxyapatite $\left(\mathrm{Ca}_{10}\left(\mathrm{PO}_{4}\right)_{6}(\mathrm{OH})_{2}\right)$ has been widely used as a bone substitute, taking into account its biocompatibility, as its mineral components are similar to those of the bones and teeth of the human body. Synthetic hydroxyapatite is an important biomaterial used in many medicine applications in bulk, as a coating, or as a component of a composite ${ }^{[2-5]}$. Many routes have been developed to synthesize the hydroxyapatite using hydrolysis, precipitation or hydrothermal methods ${ }^{[4]}$. Among these methods, the precipitation route is the most simple and cheap and, moreover, it has industrial application possibilities ${ }^{[1]}$. In the present work, hydroxyapatite was obtained by a chemical synthesis route, using aqueous solutions of ammonium phosphate and calcium nitrate and controlling parameters such as $\mathrm{pH}$, order of addition of the reagents, temperature of the mixture, ageing time and heat treatment. In order to evaluate the effect of these parameters, several syntheses were carried out, changing a variable in each test.

The intermediate and final results were evaluated by means of X-ray diffraction (XRD) and infrared Fourier transformed spectroscopy (FTIR).

\section{Experimental}

The initial aqueous solutions were prepared using tetra-hydrated calcium nitrate $\left(\mathrm{Ca}\left(\mathrm{NO}_{3}\right) .4 \mathrm{H}_{2} \mathrm{O}\right)$ (Aldrich) and ammonic phosphate $\left(\mathrm{H}_{2}\left(\mathrm{PO}_{4}\right) \mathrm{NH}_{4}\right)$ (Aldrich) in concentrations $1 \mathrm{M}$ and $0.48 \mathrm{M}$ respectively.

In order to evaluate the influence of $\mathrm{pH}$ on the final product, in the first series of tests, the $\mathrm{pH}$ of the different solutions was adjusted to 10-11 before mixing, using ammonium hydroxide (Aldrich), whereas, in those corresponding the second series, the solutions were used with their characteristic $\mathrm{pH}$ ( 6 for calcium nitrate and 8 for phosphate of ammonium) and the $\mathrm{pH}$ turned out to be 5 after mixture. Once the aqueous solutions were prepared and adjusted for $\mathrm{pH}$, they were mixed following a predetermined order (variable according to the test) 
dropping slowly a product onto the other placed in a flat bottom flask with permanent agitation of $240 \mathrm{rpm}$, continued during 3 to 9 hours. Later, the mixture was aged, either at room temperature or at $40^{\circ} \mathrm{C}$, during different times. After ageing, the precipitates were collected by filtration, washed with distilled water and dried slowly at $60^{\circ} \mathrm{C}$. The dried powders were treated at $1050^{\circ} \mathrm{C}$ during variable times and the crystalline phases in the final product were measured by XRD with a Siemens equipment (Difrac 5000 model).

With the purpose of evaluating the kinetic of the reactions and the effect of the values set for the different variables in the hydroxyapatite formation, a mixture was done in order to recover a sample in every stage of the process. The phosphate was added first in the flat bottom flask. Then, the nitrate was added slowly and immediately after the end of the nitrate addition, one section of this mixture was taken ( 0 hours mix) and after 9 hours mixing ( 9 hours mix); also, samples of the precipitate formed with different ageing periods at $40^{\circ} \mathrm{C}(24,48,72$ and 115 hours) and samples of these precipitates after washing and heating at $1050^{\circ} \mathrm{C}$ during 7 hours. These samples were analysed by FTIR spectroscopy (Perkin Elmer model 1760) in the interval of $4000-400 \mathrm{~cm}^{-1}$. For solids samples, $2 \mathrm{mg}$ of powder sample was thoroughly mixed with $200 \mathrm{mg}$ of $\mathrm{KBr}$ using a mortar and pestle, following pressing at $5 \mathrm{MPa}$ to form pellets. For liquid samples, a $\mathrm{AgCl}$ holder was employed.

\section{Results and discussion}

For initial solutions adjusted to $\mathrm{pH} 10$, addition of phosphate of ammonium to calcium nitrate, a period of agitation of 3 hours at $40^{\circ} \mathrm{C}$, an ageing period of 6 days and a heat treatment of 7 hours at $1050^{\circ} \mathrm{C}$, an incipient formation of hydroxyapatite appears with a high percentage of amorphous phase. With a much longer period of heat treatment ( 15 hours) well crystallized hydroxyapatite was obtained as the only phase in the reaction product. The $\mathrm{pH}$ plays a fundamental role in the formation of crystalline hydroxyapatite. When the $\mathrm{pH}$ of the mixture was not adjusted with the addition of ammonium hydroxide, and therefore, the synthesis was made at $\mathrm{pH}$ of 5 , the result was a mixture of somewhat amorphous calcium phosphates. In spite of that the samples were put under a heat treatment of $1050^{\circ} \mathrm{C}$ during 15 hours, there is no presence of hydroxyapatite in the final product; on the contrary, it continues the formation of an amorphous phase in an important amount. In basic $\mathrm{pH}$, the solubility decreases and the $\mathrm{OH}^{-}$presence favours the precipitation of hydroxilated calcium phosphate. For a synthesis made with initial solutions adjusted to $\mathrm{pH} \mathrm{10,} \mathrm{addition} \mathrm{of} \mathrm{calcium} \mathrm{nitrate} \mathrm{to} \mathrm{phosphate} \mathrm{of}$ ammonium, a stirring time of 9 hours, an ageing period of 3 days at $40^{\circ} \mathrm{C}$ and a heat treatment of 7 hours to $1050^{\circ} \mathrm{C}$, results in the presence of an additional crystalline phase (tricalcium phosphate $\left.{ }^{[8]}\right)$. For the initial solutions adjusted to $\mathrm{pH} 10$, addition of calcium nitrate to ammonium phosphate, period of agitation of 3 hours and ageing period of 5 days at room temperature, a heat treatment of 1 hour to $1050^{\circ} \mathrm{C}$ was enough to obtain well crystallized hydroxyapatite as the only phase.

According these results, the stirring time and the stirring and ageing temperature do not have a marked influence on the synthesis for obtaining well crystalline hydroxyapatite. The basic $\mathrm{pH}$ of the initial solutions and the final $\mathrm{pH}$ of the mixture, the order of addition of the reagents (the phosphate first) and a long period of ageing, are the more relevant parameters in the formation of well crystalline hydroxyapatite.

The nucleation and the crystal growth rates determine the appearing of crystalline phases in the synthesis of a material. Each mineral species has a characteristic kinetics of nucleation and growth that depends on the time that the reagents are allowed to play their role in the reaction. If this time is not reached, it is possible that other species (not in equilibrium) be formed, because the reactions that give origin to them are not complete. In the particular case of the hydroxyapatite, a period of ageing of 5 days was needed to obtain complete reactions in the formation and good development of the crystalline phase. In the reaction of the calcium nitrate with the ammonium phosphate to obtain hydroxyapatite, it is necessary to obtain first an equilibrium of the reagents in the aqueous media. Therefore, it is necessary to stabilize 
them before the reaction. The $\mathrm{PO}_{4}{ }^{\circ-}$ has low solubility, and this can be the reason why, when the ammonium phosphate is added to the calcium nitrate, a good amount of the reagent precipitates, and this effect does not allow the reaction with calcium for the hydroxyapatite formation. When the order of the addition of the reagents is reversed, the reaction is favoured by the high solubility of calcium nitrate.

Fig. 1 shows the FTIR for a liquid sample corresponding to the mixture at 9 hours and for solids samples corresponding to the precipitated ones after a period of ageing of 24 hours and 115 hours, to the sample after been heated at $1050^{\circ} \mathrm{C}$ during 7 hours and for the commercial hydroxyapatite (CEROS 80, USA).

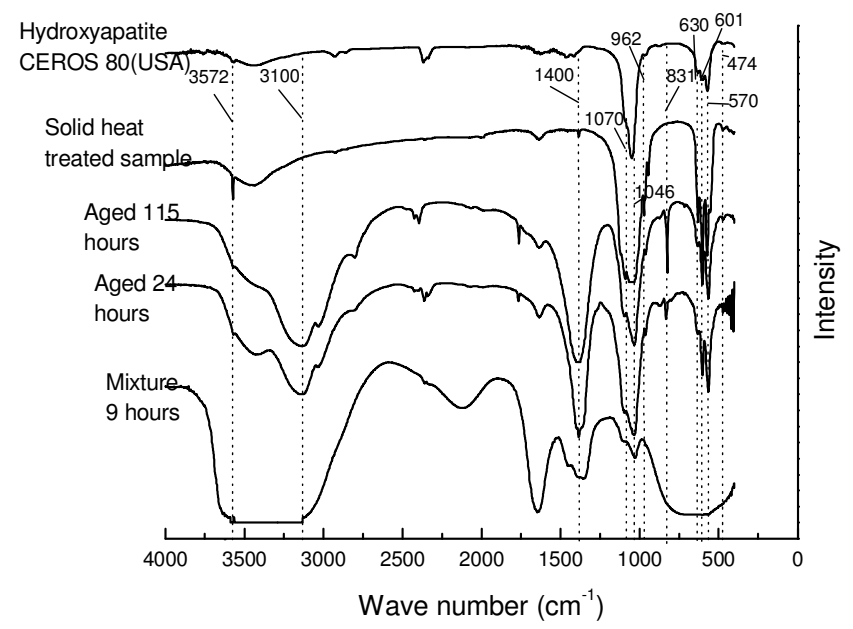

Figure 1. FTIR spectra for the liquid sample corresponding to the mixture at 9 hours and for solid samples corresponding to the precipitated ones after a period of ageing of 24 hours and 115 hours, to the sample after been heated at $1050^{\circ} \mathrm{C}$ during 7 hours and for the commercial hydroxyapatite (CEROS 80, USA)

Table 1 summarizes the FTIR frequencies and assignments for Hydroxyapatite ${ }^{[11]}$, those corresponding to commercial hydroxyapatite (CEROS 80, USA) and for all the stages of preparation of the studied sample.

Table 1. Frequencies $\left(\mathrm{cm}^{-1}\right)$ and assignments for hydroxyapatite [11], Commercial hydroxyapatite (ceros80, USA), and for all the stages of preparation of the studied sample.

\begin{tabular}{|c|c|c|c|c|c|c|c|}
\hline$\lambda\left(\mathrm{cm}^{-1}\right)$ & Assignment & Hydroxyapatite[11] & $\begin{array}{c}\text { CEROS } 80 \\
\text { (USA) }\end{array}$ & $\begin{array}{c}\text { Mixture } 9 \\
\text { hours }\end{array}$ & $\begin{array}{c}\text { Sample precipitated } \\
\text { after } 24 \text { hours of } \\
\text { ageing } \\
\end{array}$ & $\begin{array}{c}\text { Sample precipitated } \\
\text { after } 115 \text { hour of } \\
\text { ageing }\end{array}$ & $\begin{array}{l}\text { Sample after a heat } \\
\text { treatment of } 1050^{\circ} \mathrm{C} \\
\text { during } 7 \text { hours }\end{array}$ \\
\hline 3572 & $\mathrm{OH}^{-}$stretch & $\mathrm{X}$ & $\mathrm{X}$ & & & & $\mathrm{X}$ \\
\hline 3100 & $\mathrm{OH}^{-}$group & & & $\mathrm{X}$ & $\mathrm{X}$ & $\mathrm{X}$ & \\
\hline 1400 & $\mathrm{NO}_{3}^{-}$group & & & $\mathrm{X}$ & $\mathrm{X}$ & $\mathrm{X}$ & \\
\hline 1087 & \multirow{4}{*}{$\mathrm{V}_{3} \mathrm{PO}_{4}{ }^{3-}$} & \multirow{4}{*}{$\mathrm{X}$} & \multirow{4}{*}{$\mathrm{X}$} & \multirow{4}{*}{$\mathrm{X}$} & \multirow{4}{*}{$\mathrm{X}$} & \multirow{4}{*}{$\mathrm{X}$} & \multirow{4}{*}{$\mathrm{X}$} \\
\hline$\sim 1072$ & & & & & & & \\
\hline 1046 & & & & & & & \\
\hline$\sim 1032$ & & & & & & & \\
\hline 962 & $\mathrm{v}_{1} \mathrm{PO}_{4}^{3-}$ & $\mathrm{X}$ & $X$ & & & & $\mathrm{X}$ \\
\hline 831 & $\mathrm{NO}_{3}^{-}$group & & & $\mathrm{X}$ & $\mathrm{X}$ & $\mathrm{X}$ & \\
\hline 630 & $\begin{array}{c}\mathrm{OH}^{-} \\
\text {libration }\end{array}$ & $\mathrm{X}$ & $\mathrm{X}$ & \multirow{5}{*}{$\begin{array}{l}\text { Broad } \\
\text { Band }\end{array}$} & $\mathrm{X}$ (Shoulder) & $\mathrm{X}$ (Shoulder) & $\mathrm{X}$ \\
\hline 601 & $\mathrm{v}_{4} \mathrm{PO}_{4}^{3-}$ & $\mathrm{X}$ & $\mathrm{X}$ & & $\mathrm{X}$ & $\mathrm{X}$ & $\mathrm{X}$ \\
\hline 571 & & & & & & & \\
\hline 474 & \multirow[t]{2}{*}{$\mathrm{V}_{2} \mathrm{PO}_{4}^{3-}$} & \multirow{2}{*}{$\begin{array}{c}\mathrm{X} \\
\text { (shoulder) }\end{array}$} & \multirow{2}{*}{$\begin{array}{c}\mathrm{X} \\
\text { (shoulder) }\end{array}$} & & & $\mathrm{X}$ & $\mathrm{X}$ \\
\hline$\sim 462$ & & & & & & & \\
\hline
\end{tabular}

From an ageing time of 24 hours, well defined bands are observed at $570 \mathrm{~cm}^{-1}, 600 \mathrm{~cm}^{-1}$, $1046 \mathrm{~cm}^{-1}$ and $1090 \mathrm{~cm}^{-1}$ as well as a small shoulder at $630 \mathrm{~cm}^{-1}$. According to the assignments, these bands correspond to absorption modes $\mathrm{PO}_{4}$ groups ${ }^{[9]}$ in hydroxyapatite and the shoulder at $630 \mathrm{~cm}^{-1}$ corresponds to a vibrational $\mathrm{OH}^{-}$band in the same material ${ }^{[4,9]}$. The presence of these bands in samples subjected to different ageing times, indicate that hydroxyapatite structure is formed from the beginning of ageing process. The small band at $474 \mathrm{~cm}^{-1}$ and the better definition of the $\mathrm{PO}_{4}$ groups bands for an ageing time of 115 hours and for the solid heat-treated sample show the relevance of both factors in the synthesis. A 
long period of ageing and the appropriate heat treatment, make the bonds $\mathrm{PO}_{4}$ better defined in the structure of hydroxyapatite. The bands appearing at $831 \mathrm{~cm}^{-1}$ and at $1400 \mathrm{~cm}^{-1}$ on samples aged during 24 hours and 115 hours are due to $\mathrm{NO}_{3}$ groups ${ }^{[9]}$ and consequently disappear with the heat treatment.

\section{Conclusions}

- The mixture $\mathrm{pH}$ is a decisive factor in the crystallization of hydroxyapatite. A basic $\mathrm{pH}(10-$ 11) benefits in the formation of hydroxyapatite under the studied conditions of precipitation and must be controlled during the whole process .

- The order of addition of the reagents is very important. Calcium nitrate must be added slowly to the ammonium phosphate. Otherwise, the formation of pure and crystalline hydroxyapatite becomes very difficult.

- The ageing period plays an important role in the synthesis of pure hydroxyapatite. For times of ageing shorter than 5 days, three-calcium phosphate and some other calcium phosphates other not well defined amorphous phases were formed in addition to hydroxyapatite.

- The synthesis temperature does not seem to play a preponderant role in the hydroxyapatite formation. It is possible to produce pure and well crystallized hydroxyapatite from room temperature up to $40^{\circ} \mathrm{C}$.

- The heat treatment is crucial at the moment of defining the crystalline phases present in the mixture. Under the ideal conditions, it is enough to heat treat the mixture during 1 hour to synthesize pure and well crystalline hydroxyapatite. Under other conditions, it is necessary to increase the heat treatment up to 15 hours in order to obtain the desired effect.

\section{References}

[1] Liu Ch., Huang Y., Shen W., Cui J. Biomaterials, Vol 22 (2001), p. 301.

[2] Hsieh M., Chin T. J. Am. Ceram. Soc. Vol 84, (9) (2001), p. 2123.

[3] Seckler M. M., Dnese M., Darenzo S., Valarelli J.V., Giulietti M, Rodriguez-Clemente R. Mat. Res., Vol 2, (2) (1999), p.59.

[4] Weng, W., Baptista J. L. J. Eur. Ceram. Soc. Vol17, (1997), p.1151.

[5] Velayundhan, Sh., Ramesh, P., Sunny, M.C., Varma, H.K. J. Mat. Sci. Lett, Vol 46 (2000), p. 142.

[6] Santos C. Biomateriales Cerámicos I: Obtención y propiedades de biocerámicas de fosfato cálcico. PhD Thesis, Universidad de Santiago, Santiago de Compostela, España. 1994

[7] Lin, F., Chun-Jen, L., Ko-Shao, Ch., Jui-Sheng, S. J. Mat. Sci. and Eng. Vol C13 (2000), p. 97

[8] Petrov, O. E., Dyulgerova, E., Petrov L., Popova R. J. Mat. Lett., Vol 48 (2001), p. 162

[9] Liu, D., Yang, Q., Troczynski, T., Tseng, W. Biomaterials, Vol 23 (2002), p. 1679

[10] Lin, F., Liao, Ch., Chen, K., Sun, J. Biomaterials, Vol 19 (1998), p. 1101

[11] Elliot, J.C. Structure and Chemistry of the apatites and other calcium orthophosphates. Elsevier, London, 1994, pp 111-186

\section{Acknowledges}

This work has been financed through CYTED, Project VIII-9 and Network VIII-E, DINAIN project DI00C272, DIME Universidad Nacional de Colombia, and Instituto Colombiano para el Desarrollo de la Ciencia y la Tecnología -Colciencias- Grant. 1118-12-13724. 